\title{
KİMYASAL MODİFİKASYONUN ODUNDA SU ALMA, BOYUTSAL KARARLILIK VE BİYOLOJİK DAYANIMA ETKİSí
}

\author{
Eylem DIZMAN TOMAK*, Ali TEMIZ** \\ *Bursa Teknik Üniversitesi, Orman Fakültesi, Orman End. Müh. Bölümü, Merinos AKKM, 16200 Osmangazi \\ Bursa \\ **Karadeniz Teknik Üniversitesi, Orman Fakültesi, Orman End. Müh. Bölümü, 61080 Trabzon \\ evlem.dizman@btu.edu.tr, temiz@ktu.edu.tr
}

(Geliş/Received: 08.11.2013; Kabul/Accepted: 11.09.2014)

ÖZET

\begin{abstract}
Bu çalışmada, asetik, fitalik ve propiyonik anhidritler ile modifikasyon işlemine tabi tutulan odunun su alma oranı, boyutsal kararlılık ve mantar çürüklüğüne karşı performansı araştırılmıştır. Bu amaçla sarıçam odunu (Pinus sylvestris L.) örnekleri anhidritler ile muamele sonrası 2, 4 ve 8 saat boyunca $120^{\circ} \mathrm{C}$ 'de reaksiyona tabi tutulmuşlardır. Örneklerin kimyasal yapısındaki değişimler FT-IR ile, su alma oranı ve boyutsal kararlılıkları 14 gün boyunca yapılan ağırlık ve boyut ölçümleri ile, mantar çürüklüğ̈üne karşı dayanımı ise bir esmer çürüklük mantarı olan Coniophora puteana'ya 3 ay maruz bırakılmasıyla belirlenmiştir. Mantar çürüklük testinde yıkanmış ve yıkanmamış örnekler kullanılmıştır. Elde edilen bulgulara göre; anhidritler ile modifiye edilen örneklerin su alma oranı kontrol örneklerine kıyasla oldukça düşük bulunmuştur. Boyutsal kararlılık bakımından en iyi sonuçlar sırasıyla propiyonik, asetik ve fitalik anhidritler ile elde edilmiştir. Mantar çürüklük testi öncesi yıkanma işlemine tabi tutulan ve tutulmayan kontrol örneklerinde $C$. puteana saldırısı sonrasında ağırlık kaybı sırasıyla $\% 34$ ve $\% 37$ bulunurken, anhidritler ile modifiye edilen ve çürüklük testi öncesi yıkanma işlemine tabi tutulmayan örneklerde ağıllık kaybı \%0-2.1, yıkanma işlemine tabi tutulan örneklerde ise ağırlık kaybı \%0.5-7.6 olarak bulunmuștur. Esmer çürüklük mantarına karşı dayanım açısından en iyi etkinlik propiyonik anhidritle modifikasyon işlemi sonrasında elde edilmiștir.
\end{abstract}

Anahtar Kelimeler: Anhidrit, boyutsal kararlılık, FT-IR, kimyasal modifikasyon, mantar çürüklük

\section{EFFECT OF CHEMICAL MODIFICATION ON WATER ABSORPTION, DIMENSIONAL STABILITY AND BIOLOGICAL DURABILITY OF WOOD}

\begin{abstract}
In this study, effect of chemical modification using with acetic, phthalic and propionic anhydrides on water absorption, dimensional stability and biological resistance of wood was studied. For this purpose, Scots pine (Pinus sylvestris L.) wood samples were treated with the anhydrides and heated at $120^{\circ} \mathrm{C}$ during 2,4 and 8 hours after treatment. Chemical changes in wood were investigated with FT-IR. Dimensional stability and water absorption rates of samples were determined by weighting the samples and measuring the dimensions during 14 days in water submersion test. Decay test was performed using a brown rot fungus, Coniophora puteana for 3 months on both leached and unleached samples. According to results, water absorption rate of treated wood was lower than that of untreated controls. The best results for anti-shrink efficiency were found in propionic, acetic and phthalic anhydride treatments, respectively. The weight loss of samples exposed to C. puteana was found as $34 \%$ and $37 \%$ for unleached and leached controls, respectively. The weight loss values were in a range of $0-$ $2.1 \%$ and $0.5-7.6 \%$ for unleached and leached modified samples, respectively. Propionic anhydride showed better decay resistance against decay fungus compared to other anhydrates.
\end{abstract}

Key words: Anhydride, dimensional stability, FT-IR, chemical modification, fungal decay 


\section{GİRIŞ (INTRODUCTION)}

Kimyasal modifikasyon yöntemi odunun boyutsal kararlılığını ve mantar çürüklüklerine karşı dayanımını arttırmak için etkili bir yöntemdir. $\mathrm{Bu}$ amaçla asit anhidritler kullanılabilmekte olup, odun bileşenleri ile anhidritler arasında ester bağları oluşmaktadır [1]. Kimyasal modifikasyon yöntemleri arasında en çok çalışılan asetik anhidritin kullanıldığ 1 asetillendirme yöntemi olmuştur [1]. Asetillendirme yöntemi ile higroskopisite azalmakta [2], boyutsal kararlılık artmakta [3-6], tünel açan bakterilere, esmer, beyaz ve yumuşak çürüklüğe karşı dayanım iyileşmektedir [6-11]. Asetillendirilmiş odun zehirlilik özelliği göstermemekte ve çevreye karşı zararlı etkileri bulunmamaktadır [12]. Bu açıdan kimyasal modifikasyon yöntemleri bakır esaslı emprenye maddeleri ve diğer emprenye maddelerine alternatif bir koruma yöntemi olarak ele alınabilmektedir. Asetillendirme, kimyasal modifikasyon yöntemleri içinde ticari öneme sahip bir yöntemdir. Asetik anhidrit dışında diğer anhidritler (propionik, bütirik, valerik, hekzonik, heptanoik, maleik, fitalik, süksinik vb.) üzerinde de son yıllarda yapılan çalışmalar mevcuttur [13-26]. Asetik anhidritle aynı muamele koşullarında propiyonik anhidrit kullanılarak gerçekleştirilen modifikasyon işleminde daha iyi bir boyutsal kararlılık elde edilmiştir [14]. Odunun propiyonik anhidrit modifikasyonu ile mantar çürüklüklerine karşı iyi bir biyolojik dayanım elde edilmiştir [15]. Ökaliptus odununun propiyonik anhidrit ile \%26 ağırlık artışı değeri verecek şekilde gerçekleştirilen modifikasyon işleminde \%83 oranında daralmaya veya şişmeye karşı etkinlik derecesi (ASE) kazandırılmıştır [26]. Fitalik, maleik, süksinik ve asetik anhidritin kullanıldığ 1 ve $1 s ̧ 1 k$ stabilitesinin incelendiği çalışmada fitalik anhidrit diğer anhidritlere kıyasla daha kötü sonuçlar vermiştir [17]. Asetik anhidritin maleik ve fitalik anhidrite kıyasla odunun higroskopisitesini daha fazla azalttığı bulunmuştur [18]. Asetik, maleik, süksinik ve fitalik anhidritlerle modifiye edilen yongalevhada su alma oranı ve kalınlık artışı değerleri bakımından en iyi sonuçlar sırasıyla asetik, süksinik, fitalik ve maleik anhidrit ile elde edilmiştir [23].

Bu çalışmada, asetik, propiyonik ve fitalik anhidritler ile emprenye edilen ve ardından 2, 4 ve 8 saat boyunca $120^{\circ} \mathrm{C}$ 'de modifiye edilen sarıçam odunu örneklerinin su alma oranı, boyutsal kararlılığı ve mantar çürüklüğüne karşı dayanımı belirlenmiştir. Mantar çürüklüğüne karşı dayanım yıkanmış ve yıkanmamış örnekler için bir esmer çürüklük mantarı olan C. puteana'ya maruz bırakılarak belirlenmiştir. Modifikasyon işlemine tabi tutulan örneklerin kimyasal yapısındaki değişimler ise FT-IR spektroskopisi ile karakterize edilmiştir.
2.MATERYAL VE METOT (MATERIAL AND METHOD)

2.1. Odun Örnekleri ve Anhidritlerle Modifikasyon İşlemi (Wood Samples and Modification Process with Anhydrides)

Sarıçam (Pinus sylvestris L.) diri odun örnekleri $20 \mathrm{x}$ $20 \times 10 \mathrm{~mm}$ (radyal, teğet, lifler yönü) boyutlarında kesilerek $\% 65$ bağll nem ve $20^{\circ} \mathrm{C}$ 'de 2 hafta süreyle kondisyonlanmıştır. Örnekler modifikasyon işlemi öncesinde $80^{\circ} \mathrm{C}^{\prime}$ de 24 saat boyunca tam kuru hale getirilerek ağırlıkları $\left(\mathrm{M}_{\mathrm{mö}}\right)$ ve boyutları ölçülmüştür. Her grup için 14 örnek tekrarı kullanılmıştır. Asetik anhidrit (AA) ksilenle 1/1 (v/v) oranında [27], fitalik anhidrit (FA) ise ksilenle $1 / 6(\mathrm{w} / \mathrm{v})$ oranında [23] karıştırılarak $500 \quad \mathrm{ml}$ çözelti emprenye için hazırlanmıştır. Propiyonik anhidrit (PA) ise seyreltme işlemi olmadan direkt olarak kullanılmıştır. Tam kuru haldeki odun örnekleri asetik, propiyonik ve fitalik anhidritlerle $45 \mathrm{dk}$ vakum altında emprenye edilmiş ardından vakum kapatılarak $60 \mathrm{dk}$ çözelti içerisinde bekletilmiştir. Süre sonunda emprenye sisteminden çıkarılan örnekler üzerindeki fazla çözelti alınmış, örnekler alüminyum folye ile sarılarak $120^{\circ} \mathrm{C}$ 'deki bir etüvde 2, 4 ve 8 saat boyunca modifiye edilmiştir. Modifikasyon işlemi sonrasında örnekler $\% 65$ bağıl nem ve $20^{\circ} \mathrm{C}$ 'deki iklimlendirme dolabinda 1 hafta bekletilmiş, ardından $80^{\circ} \mathrm{C}$ 'de 24 saat kurutularak tam kuru ağırlıkları $\left(\mathrm{M}_{\mathrm{ms}}\right)$ ve boyutları belirlenmiş ve ağırlık artış değerleri (AAD, \%) 1 nolu eşitlik yardımıyla hesaplanmıştır.

$A A D=\left[\left(M_{m s}-M_{m \ddot{o}}\right) / M_{m \ddot{o}}\right] \times 100$

2.2. Fourier Transform Infrared (FT-IR) Spektroskopi Analizi (Fourier Transform Infrared (FTIR) Spectroscopy Analyze)

Modifikasyon işlemine tabi tutulan ve tutulmayan odun örnekleri ögütüldükten sonra potasyum bromür $(\mathrm{KBr})$ ile karıştırılmış ve preslenerek ince bir palet haline getirilmiştir. Paletlerin spektrası Perkin Elmer Spectrum One FT-IR spectroscopy model 2000 cihazı ile $1900-600 \mathrm{~cm}^{-1}$ dalga boyu aralı̆ğında, 32 tarama ile $8 \mathrm{~cm}^{-1}$ rezolüsyonda alınmıştır.

2.3. Su Alma Oranının ve Boyutsal Kararlılığın Belirlenmesi (Determination of Water Absorption Rates and Dimensional Stabilization)

Her gruba ait 6 adet test (modifikasyon işlemine tabi tutulan) örneği ve 20 adet kontrol (modifikasyon işlemine tabi tutulmayan) örneği 2 hafta boyunca oda sıcaklığındaki saf su içerisinde bekletilmiştir. $\mathrm{Bu}$ örnekler ayrıca mantar çürüklük testinde yıkanmış örnek olarak da değerlendirilmiştir. Örneklerin tam radyal ve teğet yönleri içermesine dikkat edilmiştir. Belirli sürelerde $(6,24,48$ ve her 48 saatte bir) örnekler sudan çıkarılmış, üzerlerindeki fazla su silinerek kurulanmış, ağırlıkları ve boyutları ölçülmüş̧ür. Her sudan çıkarma süresine ait örneklerin su alma oranı (SAO, \%) ve boyutsal 
kararlılık (BK, \%) 2 ve 3 nolu eşitlikler yardımıyla hesaplanmıştır.

$$
\begin{aligned}
& S A O=\left[\left(M_{2}-M_{l}\right) / M_{l}\right] \times 100 \\
& B K=\left[\left(S_{k}-S_{t}\right) / S_{k}\right] \times 100
\end{aligned}
$$

Eşitliklerde; $\mathrm{M}_{1}$ : Başlangıçtaki tam kuru ağırlık (g), $\mathrm{M}_{2}$ : Her periyot sonrasında sudan çıkarılan örneğin ağırlığ $(\mathrm{g}), \mathrm{S}_{\mathrm{t}}$ : Test örneklerinin hacimsel genişleme katsayısı, $S_{\mathrm{k}}$ : Kontrol örneklerinin hacimsel genişleme katsayısını ifade etmektedir.

\subsection{Mantar Çürüklük Testi (Decay Test)}

Çalışmada EN 113 [28] çürüklük testi, modifiye edilerek esas alınmıştır. Deney öncesi örnekler $80^{\circ} \mathrm{C}$ 'de değişmez ağırlığa gelinceye kadar bekletilmiş ve tam kuru ağırlıkları $\left(\mathrm{M}_{c ̧ o ̈)}\right.$ belirlenmiştir. Çürüklük testi yıkanmış, yıkanmamış test ve kontrol örneklerine 4 tekrarlı olmak üzere agar ortamında esmer çürüklük mantarı Coniophora puteana (Schum.:Fr.) Karst. Mad-515 kullanılarak uygulanmıştır. Mantar miseli kaplı her bir kavanoza 1 test ve 1 kontrol örneği yerleştirilmiştir. 12 hafta boyunca $20^{\circ} \mathrm{C}$ ve $\% 65$ bağıl nemli bir odada mantar saldırısına birakılan örneklerin, deney sonrasında tam kuru ağırlıkları $\left(\mathrm{M}_{\mathrm{cs}}\right)$ belirlenerek ağırlık kayıpları (\%) (4) nolu eşitlik yardımıyla hesaplanmış ve biyolojik dayanım özellikleri değerlendirilmiştir.

A ğırlık kayıpları $=\left[\left(M_{c ̧ \ddot{o}}-M_{c s}\right) / M_{c ̧ \ddot{o}}\right] \times 100$

\section{BULGULAR VE TARTISMMA (RESULTS AND DISCUSSION)}

Modifikasyon işlemine tabi tutulan örneklerin ortalama ağırlık artışı değerleri (\%), standart sapma değerleriyle birlikte Tablo 1'de gösterilmiştir.

Tablo 1. Modifikasyon işlemine tabi tutulan örneklerin ağırlık artış değerleri (Weight percent gain of modified samples)

\begin{tabular}{lll}
\multicolumn{2}{l}{ Test Grupları } & Ağırlık Artış1 (\%) \\
\hline AA & $2 \mathrm{~s}$ & $11,55(0.68)^{*}$ \\
& $4 \mathrm{~s}$ & $12,74(0.44)$ \\
& $8 \mathrm{~s}$ & $13,38(0.81)$ \\
$\mathrm{PA}$ & $2 \mathrm{~s}$ & $14,98(1.76)$ \\
& $4 \mathrm{~s}$ & $15,03(1.52)$ \\
& $8 \mathrm{~s}$ & $16,07(1.12)$ \\
$\mathrm{FA}$ & $2 \mathrm{~s}$ & $11,36(0.88)$ \\
& $4 \mathrm{~s}$ & $13,40(0.89)$ \\
& $8 \mathrm{~s}$ & $10,61(0.60)$ \\
\hline
\end{tabular}

* Parantez içindeki değerler standart sapmayı göstermektedir.

Reaksiyon süresine bağlı olarak, asetik, propiyonik ve fitalik anhidritlerle modifikasyona uğratılan örneklerin ağırlık artışı değerleri sırasıyla \%11.6-13.4,
\%15-16 ve \%10.6-13.4 olarak bulunmuştur. Ağırlık artış değerleri propiyonik anhidritle modifiye edilen örneklerde daha yüksek elde edilmiştir. Fitalik anhidritle 8 saat işlem gören örnekler hariç modifikasyon süresi arttıkça örneklerin ağırlık artışı değerleri hafifçe artmaktadır. Ancak reaksiyon süresine bağlı olarak değişim gösteren ağırlık artışı değerleri arasında büyük farklılıklar gözlenmemektedir.

Sıcaklık ve reaksiyon süresi ağırlık artışı değerleri üzerinde önemli bir rol oynamakta ve çoğu kez asetillendirilmiş odunun özellikleri asetillendirme yöntemine bağlı olmaktadır [29]. $\mathrm{Bu}$ araştırma makalesinde, reaksiyon sicaklığı sabit $\left(120^{\circ} \mathrm{C}\right)$ tutulmuştur.

Sıcaklık ve reaksiyon süresi ağırlık artışı değerleri üzerinde önemli bir rol oynamakta ve çoğu kez asetillendirilmiş odunun özellikleri asetillendirme yöntemine bağlı olmaktadır [29]. $\mathrm{Bu}$ araştırma makalesinde, reaksiyon sicaklığ sabit $\left(120^{\circ} \mathrm{C}\right)$ tutulmuştur. Bunun temel nedeni, asetillendirme reaksiyonlarında bu sıcaklığın kabul edilebilir en yüksek sıcaklık olmasıdır. Bu sıcaklığın üzerindeki uygulamalarda, hücre çeperinin önemli ölçüde degradasyonu söz konusudur [11]. Ağırlık artış değerleri, reaksiyonun devam ettiği 1 saat boyunca artış göstermekte ve süre arttıkça ağırlık artışı değerlerinde çok az artışlar gözlenmektedir. Reaksiyon süresinin 1 saatten 5 saate çıkmasıyla ağırlık değerlerindeki artış oranı \%1,3'den \%1,4'e çıktığı bildirilmektedir [29]. Rowell ve ark. [30] reaksiyon hizının, $120^{\circ} \mathrm{C}$ 'de 1 saat boyunca hizlı devam ettiğini, reaksiyon süresinin artmasiyla reaksiyon hızının azaldığını, bu durumun reaksiyon sırasında asetik asidin yan ürün olarak eldesinden kaynaklandığını belirtmiştir. Çalışmada asetik anhidrite benzer şekilde propiyonik ve fitalik anhidritlerin kullanımında da benzer eğilimler gözlenmiştir. $\mathrm{Bu}$ duruma neden reaksiyon süresinin artmasıyla birlikte anhidritler ile reaksiyona giren hücre çeperindeki hidroksil gruplarının azalması gösterilebilir. Çetin ve ark. [26], propiyonik anhidritle yaptıkları çalışmada 120 dakika sonunda \%22 seviyelerinde ağırlık artış değerleri elde ederken, sürenin arttırılmasının ağırlık artışı değerleri üzerinde düşük bir etki yaptığını ve 6 saatlik reaksiyon süresi sonunda \%26 ağırlık artış değeri elde ettiklerini rapor etmiştir.

Modifikasyona tabi tutulan örneklere ait FT-IR spektraları Şekil 1'de asetik anhidrit için, Şekil 2'de propiyonik anhidrit için, Şekil 3'de fitalik anhidrit için gösterilmektedir. 


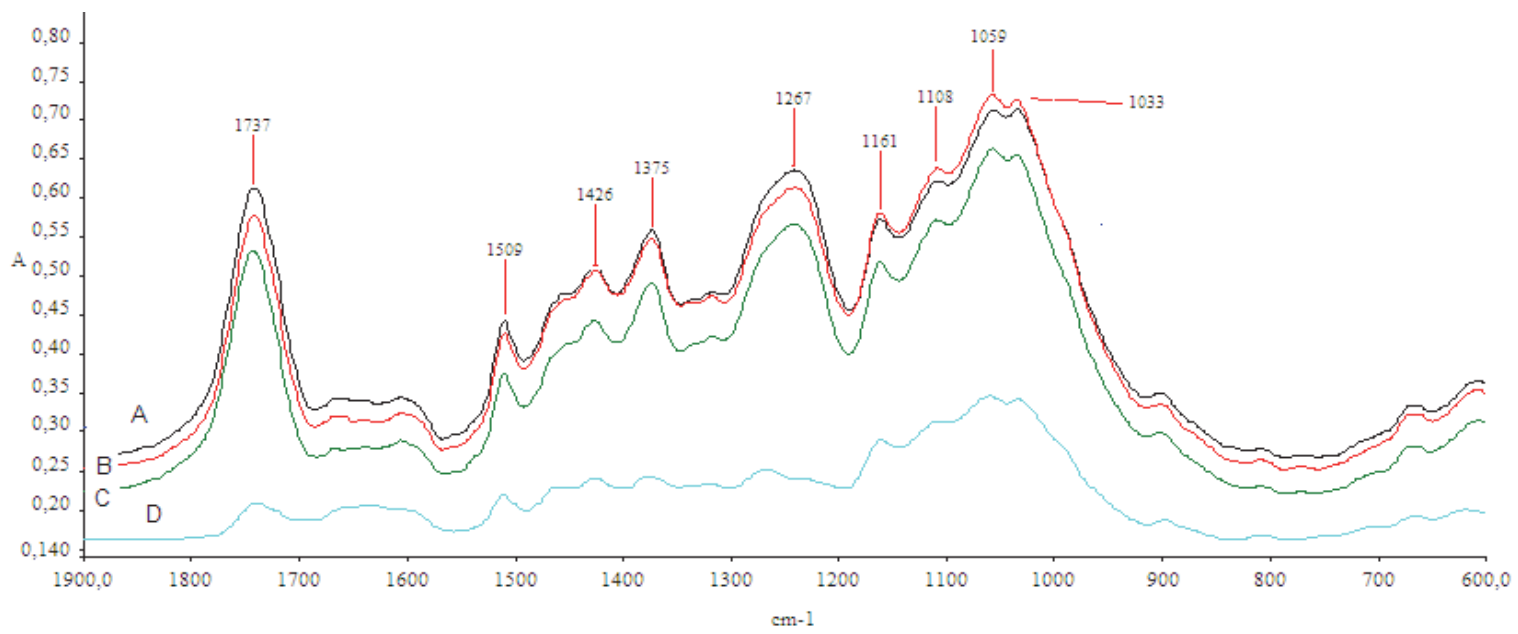

Şekil 1. Asetik anhidrit ile modifiye edilen örneklere ait FT-IR spektrası, A: AA-8s, B: AA-2s, C: AA-4s, D: Kontrol (FTIR spectra of acetic anhydride modified wood, A: AA-8h, B: AA-2h, C: AA-4h, D: Control)

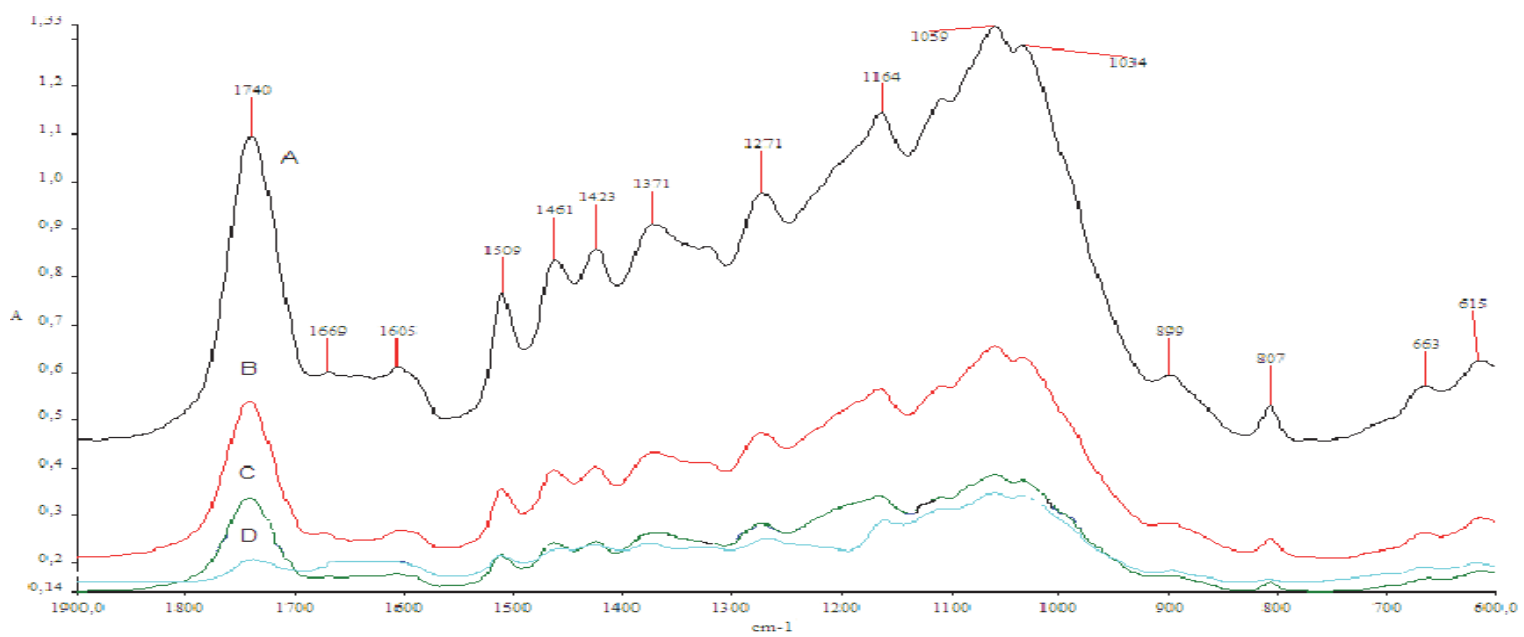

Şekil 2. Propiyonik anhidrit ile modifiye edilen örneklere ait FT-IR spektrası, A: PA-2s, B: PA-4s, C: PA-8s,

D: Kontrol (FTIR spectra of propionic anhydride modified wood, A: PA-2h, B: PA-4h, C: PA-8h, D: Control)

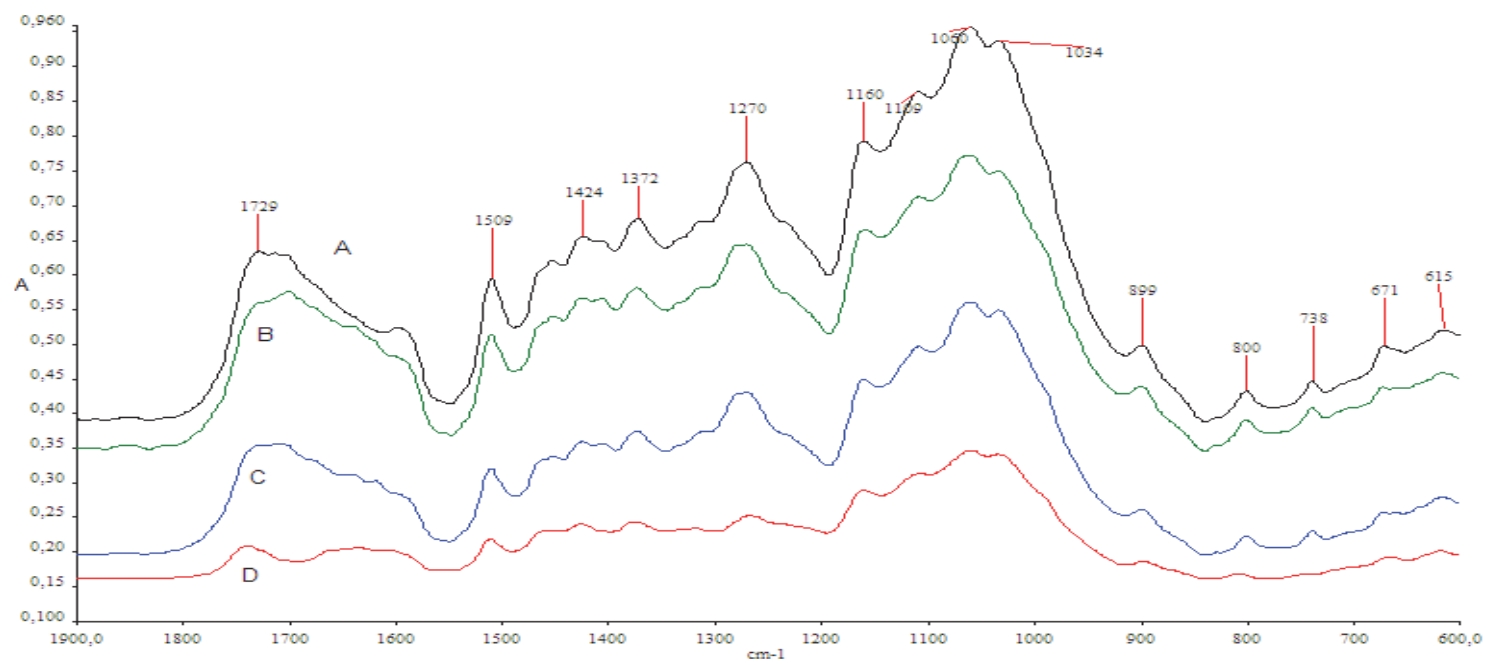

Şekil 3. Fitalik anhidrit ile modifiye edilen örneklere ait FT-IR spektrası, A: FA-4s, B: FA-2s, C: FA-8s, D: Kontrol (FTIR spectra of phthalic anhydride treated wood, A: FA-4h, B: FA-2h, C: FA-8h, D: Control)

Modifikasyon sonrasında örneklerin 1720-1740, $1595,1508,1460,1425,1370,1265,1160,1060$ ve $890 \mathrm{~cm}^{-1}$ absorpsiyon piklerinde önemli değişiklikler gözlenmiştir.
$\mathrm{Bu}$ değişiklikler fonksiyonel gruplar ve odun bileşenlerinin kimyasal yapısındaki değişiklikler ile ilgilidir. IR spektraların absorpsiyon pikleri ve fonksiyonları ise Tablo 2'de verilmiştir [31-33]. 1595 
ve $1510 \mathrm{~cm}^{-1}$, deki absorpsiyon, ligninin aromatik halkalarındaki $\mathrm{C}=\mathrm{C}$ gerilmesi ile, $1265 \mathrm{~cm}^{-1}$, deki absorpsiyon lignindeki guasil halkasındaki titreşim ile ilgilidir. Modifikasyon işlemi sonrasında özellikle $1510 \mathrm{~cm}^{-1}$, deki absorpsiyon piklerinde artışlar olduğu gözlenmiştir. $1460 \mathrm{~cm}^{-1}$ absorpsiyon piki özellikle propiyonik anhidritle modifiye edilen örnekler artış göstermekte olup lignin yapısında bir deformasyonu belirtmektedir. $\mathrm{C}=\mathrm{O}$ gerilimi (hemiselülozlardaki ksilanlar) nedeniyle ortaya çıkan 1710-1745 $\mathrm{cm}^{-1}$ absorpsiyon band1, modifiye edilen örneklerde artmıştır. Karbonil pikindeki artış, modifikasyon işlemleri nedeniyle ester üretimine atfedilmiştir [34]. Propiyonik anhidrit ile modifiye edilmiş odun örneklerinin spektrasında, propil grubunun odunun hidroksil grubuna ester bağı ile bağlanması $1742 \mathrm{~cm}^{-}$ ${ }^{1}$, de oluşan yeni pik ile ispatlanmakta ve bu pik oduna bağlanan karbonil gruplarından $(\mathrm{C}=\mathrm{O})$ kaynaklanmaktadır [26]. ]. Modifiye edilen örneklerin $1425,1370,1160,1060$ ve $890 \mathrm{~cm}^{-1}$ absorpsiyon bandlarında artışlar gözlenmiştir. $\mathrm{C}=\mathrm{O}$ ve $\mathrm{C}-\mathrm{O}$ bandındaki değişimler, selüloz ve hemiselülozun hidroksil grupları arasında kimyasal bir reaksiyon olduğunu göstermektedir. Fitalik anhidrit ile modifiye edilen örneklerde kontrol örneklerine kıyasla absorpsiyon piklerindeki artış 4 saatlik reaksiyon süresi sonrasında daha fazla olmuştur. Bu artışı 2 saatlik reaksiyon süresi takip etmektedir. Propiyonik anhidrit ile modifiye edilen örneklerde süre arttıkça pik artışında azalmalar bulunmuştur. Reaksiyon süresinin asetik anhidritle modifikasyona tabi tutulan örneklerin kimyasal yapısı üzerinde önemli etkisi olmamıştır. Bu durum daha önce de ifade edildiği gibi modifikasyon işlemlerinde ilk saatlerin daha önemli bir rol oynamasından kaynaklanmış olabilir.

Tablo 2. IR spektraların absorpsiyon pikleri ve fonksiyonları (Assignments of absorption IR spectra bands in wood)

\begin{tabular}{|c|c|}
\hline Dalgaboyu $\mathrm{cm}^{-1}$ & Grup ve Sınıfı ile Fonksiyonları \\
\hline $1720-1740$ & Ksilanda $\mathrm{C}=\mathrm{O}$ gerilimi \\
\hline $1595 \pm 5$ & $\begin{array}{l}\text { Ligninin aromatik halkalarındaki } \\
\mathrm{C}=\mathrm{C} \text { gerilmesi }\end{array}$ \\
\hline $1510 \pm 5$ & $\begin{array}{l}\text { Ligninin aromatik halkalarındaki } \\
\mathrm{C}=\mathrm{C} \text { gerilmesi }\end{array}$ \\
\hline $1450-1470$ & $\begin{array}{l}\text { Ligninde } \mathrm{CH}_{3} \text { deformasyonu ve } \\
\text { ksilanda } \mathrm{CH}_{2} \text { eğilmesi }\end{array}$ \\
\hline $1425 \pm 5$ & Selülozda $\mathrm{CH}_{2}$ sallantısı \\
\hline $1370 \pm 5$ & $\begin{array}{l}\text { Selüloz ve hemiselülozda } \mathrm{CH}_{2} \\
\text { eğilmesi }\end{array}$ \\
\hline $1265 \pm 5$ & $\begin{array}{l}\text { Lignindeki guasil halkasında } \\
\text { titreşim }\end{array}$ \\
\hline $1157 \pm 5$ & $\begin{array}{l}\text { Selüloz ve hemiselülozda C-O-C } \\
\text { asimetrik band } 1\end{array}$ \\
\hline $1056-1083$ & $\begin{array}{l}\text { Selüloz ve hemiselülozda C-O } \\
\text { gerilmesi }\end{array}$ \\
\hline $890-899$ & $\begin{array}{l}\text { Selüloz ve hemiselülozda } \mathrm{C} 1 \\
\text { grubunun sayıs1 }\end{array}$ \\
\hline
\end{tabular}

Anhidrit modifikasyonuna tabi tutulan test örnekleri ile kontrol örneklerine ait ortalama su alma oranı değerleri (\%) Şekil 4'de gösterilmiştir. Test örneklerinin su alma oranı değerleri kontrol örneklerinden daha düşük bulunmuştur. Reaksiyon süresine bağlı olarak, 2. hafta sonunda su alma oranı değerleri asetik anhidrit ile modifiye edilen örnekler için \% 141-156, propiyonik anhidritle modifiye edilen örnekler için \%137-139, fitalik anhidritle modifiye edilen örnekler için \%126-135 aralığında bulunmuştur. $\mathrm{Bu}$ değer kontrol örnekleri için \%192'dir. Test ve kontrol örneklerinin 2 hafta boyunca su alma oranı düzenli olarak artış göstermiş ve modifiye edilen örnekler su itici etkinlik göstermemiştir. Nitekim odunun kimyasal modifikasyonunda temel amaç ve sağlanan fayda odunun su itici etkinliğinin sağlanmasından öte boyutsal kararlılığının sağlanmasıdır. Kimyasal modifikasyon işleminde odundaki hidroksil grupları ile anhidritler reaksiyona girerek, $\mathrm{OH}$ grupları bloke edilir. Bu konu ile ilgili literatürde çeşitli çalışmalar mevcuttur [11, 35, 36]. Reaksiyon süresinin odunun su alma oranı üzerinde dikkat çekici önemli bir etkisi olmamıştır. Reaksiyon süresi arttıkça asetik anhidrit ile modifiye edilen örneklerde su alma oranı hafifçe azalmıştır. Bu durum 144. saatten itibaren biraz daha net olarak gözlenmektedir. Propiyonik anhidrit ile modifiye edilen örneklerde reaksiyon süresinin etkili olmadığ 1 bulunmuştur. Fitalik anhidritle modifiye edilen örneklerde 2 ile 4 saat reaksiyon süresi birbirine yakın değerler verirken, 8 saatlik reaksiyon süresi daha fazla su alma oranı değeri sergilemiştir.

Modifiye edilen örneklere ait boyutsal kararlılık değerleri (\%) Şekil 5'de gösterilmiştir. Modifiye edilen örnekler arasında en iyi boyutsal kararlılık propiyonik ve asetik anhidrit kullanımında sağlanmıştır. Reaksiyon süresine bağlı olarak, 2. hafta sonunda sağlanan boyutsal kararlılık değerleri asetik anhidrit ile modifiye edilen örnekler için \%53-60, propiyonik anhidritle modifiye edilen örnekler için \%55-64 ve fitalik anhidritle modifiye edilen örnekler için \%18-23 aralığında bulunmuştur. 2 hafta boyunca boyutsal kararlılık değerleri asetik ve propiyonik anhidritle modifiye edilen örnekler için daha stabil özellik gösterirken, fitalik anhidrit ile modifiye edilen örnekler için sürekli azalma eğilimindedir. Fitalik anhidrit ile muamele edilen örneklerin düşük boyutsal kararlılık göstermesi fitalik anhidritin stabil olmayan yapısı ve zayıf ester bağları oluşturmasından kaynaklanmaktadır [37].

$\mathrm{Bu}$ durum modifiye edilen örneklerin yüksek rutubetli koşullarda kısmi de-esterleşmesine atfedilmiştir [38]. De-esterleşme, yeni absorpsiyon gruplarının oluşmasına imkan verdiği gibi, odunun higroskopisitesini arttırıcı dikarboksilik asitlerin ayrılmasına da neden olmaktadır [18]. Asetik ve propiyonik anhidritle modifiye edilen örneklerde reaksiyon süresinin artması ile daha iyi bir boyutsal kararlılık sağlamıştır. Modifiye edilen örneklerde en iyi etkinlik propiyonik anhidritle 8 saatlik reaksiyon süresinde elde edilmiştir. Fitalik anhidritle modifiye 


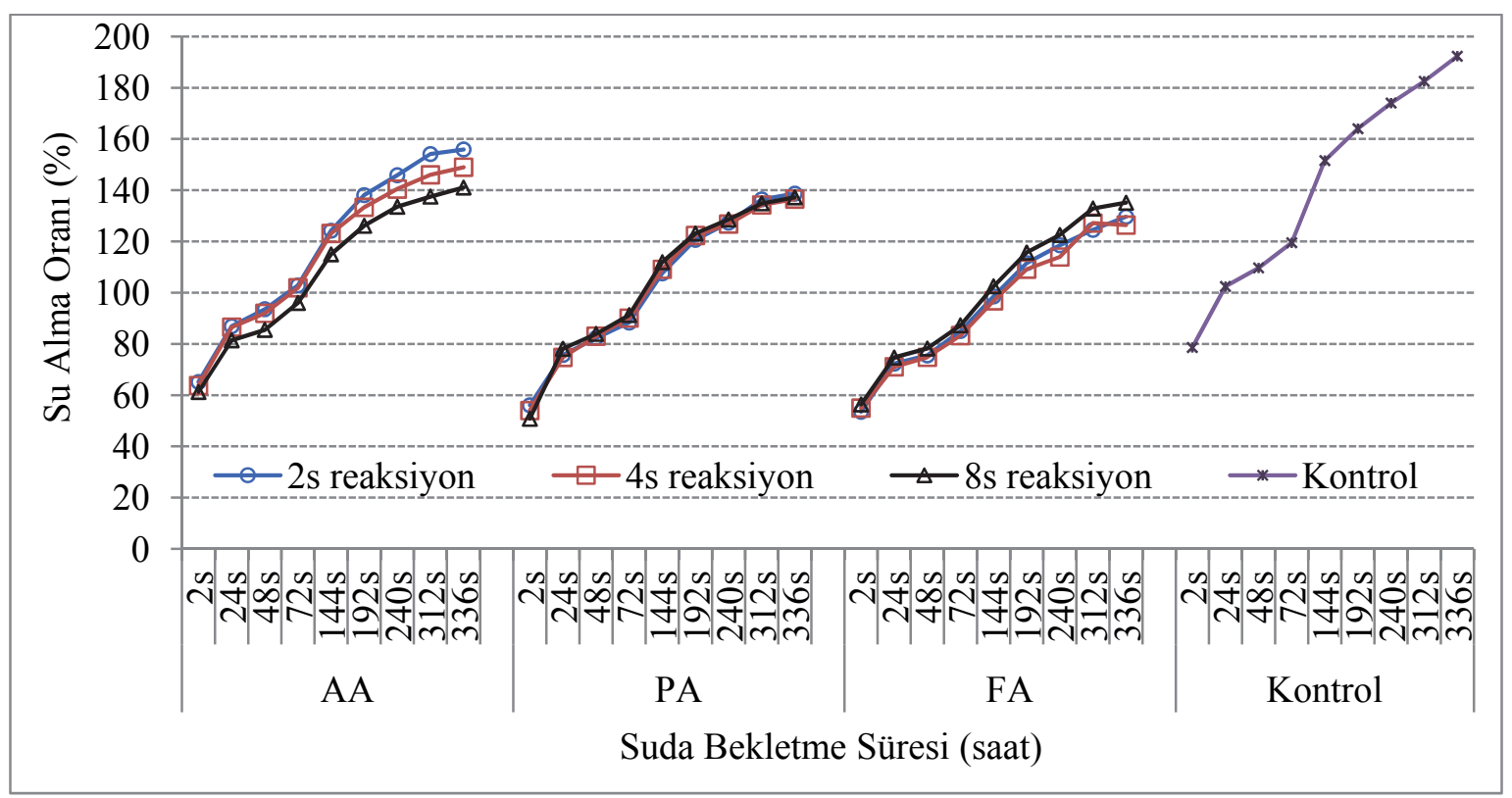

Şekil 4. Modifikasyon işlemine tabi tutulan test örnekleri ile kontrol örneklerinin suda bekletme sürelerine göre su alma oranı değerleri (Water absorption rates of modified and unmodified wood during the immersion tests)

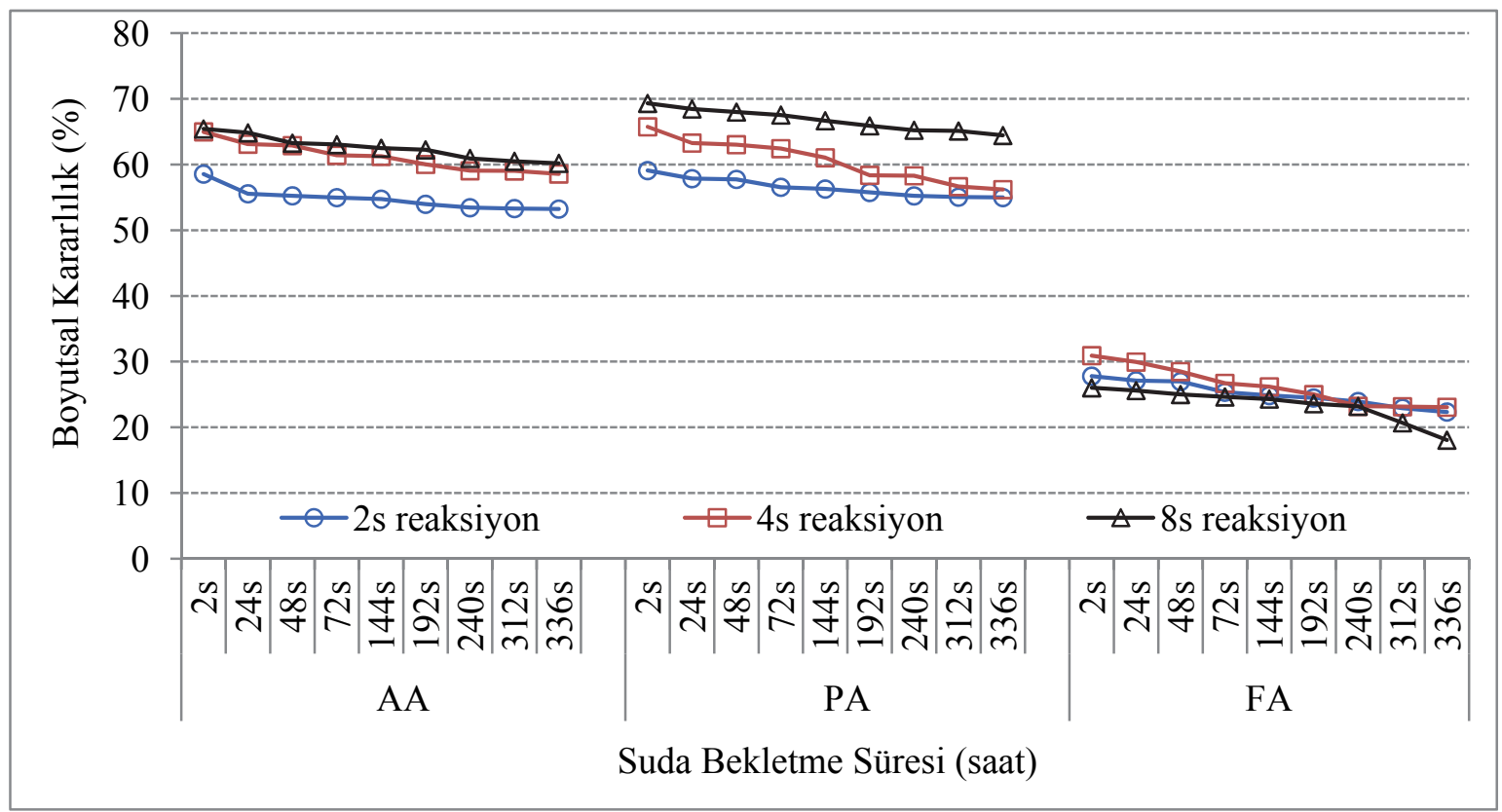

Şekil 5. Modifiye edilen örneklerin suda bekletme sürelerine göre boyutsal kararlllık değerleri (Dimensional stabilization of modified wood during the immersion tests)

edilen örneklerde ise boyutsal kararlılık tüm reaksiyon sürelerinde benze şekilde bulunmuştur. $C$. puteana mantarının saldırısına maruz birakılan örneklerin ağırlık kaybı değerleri (\%) Tablo 3'de gösterilmiştir.

Sarıçam kontrol örneklerinde $C$. puteana mantar saldırısı nedeniyle oluşan ağırlı kayıpları yıkanmamış örnekler için \%34, yıkanmış örnekler için \%37'dır. Ağırlık kayıpları \%20'nin üstünde olduğu için yapılan çürüklük testi EN 113 standardına [28] göre başarılı sayılmıştır.
Tablo 3. Mantar çürüklük testi sonrasında örneklerdeki ağırlık kayıpları (Mass-loss of the samples after decay test)

\begin{tabular}{llll}
\multicolumn{2}{l}{ Test Gruplar1 } & Y1kanmamış & Y1kanmış \\
\hline AA & $2 \mathrm{~s}$ & $0,67(0,5)$ & $6,66(1,10)$ \\
& $4 \mathrm{~s}$ & $0,4(0.11)$ & $3,09(1,09)$ \\
$\mathrm{PA}$ & $8 \mathrm{~s}$ & $0(0,01)$ & $0,52(0,39)$ \\
& $2 \mathrm{~s}$ & $0,35(0,23)$ & $2,94(1,76)$ \\
& $4 \mathrm{~s}$ & $0,23(0,26)$ & $1,15(1,86)$ \\
FA & $8 \mathrm{~s}$ & $0(0,01)$ & $0,80(1,02)$ \\
& $2 \mathrm{~s}$ & $2,10(0,85)$ & $7,56(0,84)$ \\
& $4 \mathrm{~s}$ & $1,24(0,43)$ & $6,93(2,84)$ \\
Kontrol & $8 \mathrm{~s}$ & $0,35(0,59)$ & $2,39(0,56)$ \\
\hline
\end{tabular}


Test örnekleri kontrol örneklerine kıyasla oldukça düşük ağırlık kaybı değerleri vererek iyi bir biyolojik dayanım özelliği sergilemişlerdir. Çürüklük testi sonrasında, test örneklerinde şekilsel ve boyutsal olarak gözlenebilen bir değişiklik olmamış ve örnekler orijinal halini (sağlam) korumuştur. Asetik anhidritle modifiye edilen örneklerin yıkanmamış grubunda ağırlık kayıpları reaksiyon süresine bağlı olarak \%0-0,7, yıkanmış grubunda \%0,5-6,7; propiyonik anhidritle modifiye edilen örneklerin yıkanmamış grubunda ağırlık kayıpları \%0-0,4, yıkanmış grubunda \%0,5-3; fitalik anhidritle modifiye edilen örneklerin yıkanmamış grubunda ağırlık kayıpları \%0,4-2,1, yıkanmış grubunda \%2,4-7,6 olarak bulunmuştur. Yıkanmış grupta daha yüksek ağırlık kayıpları elde edilmiştir. Fitalik anhidrit ile modifikasyon işlemine tabi tutulan örneklerin ağırlık kayıpları diğer anhidritlere nazaran daha yüksek çıkmıştır. Bu durum yapılan boyutsal kararlılık testlerinde de belirtildiği gibi fitalik anhidritin deesterleşmesi sonucu odunun higroskopisitesini arttırıcı etkiden kaynaklanmaktadır. Çünkü anhidritler ile modifiye edilen örneklerde mantara karşı dayanım, odunun higroskopisitesinin azalmasıyla ilgili olabilir. Odunda sağlanan bu etki, odun hücre çeper polimerlerine suyun girmesini engellemekte böylece odunun enzimatik hidrolizini engelleyerek biyolojik dayanım kazandırmaktadır [39]. Diğer iki grupta, reaksiyon süresi arttıkça ağırlık kayıpları azalmıştır. En düşük ağırlık kaybı değeri ve dolayısı ile en iyi biyolojik dayanım özelliği, boyutsal kararlılık değerleri gibi propiyonik anhidritle modifiye edilen örnek grubunda gözlenmiştir.

\section{SONUÇLARIN (CONCLUSION)}

Kimyasal modifikasyon teknikleri, odun çürütücü mantarlara karşı biyolojik dayanımı arttırma ve oduna boyutsal kararlılık özelliği kazandırmaları nedeniyle etkili ve çevre dostu yöntemler olarak önem kazanmaktadır. Bu çalışmada asetik, propiyonik ve fitalik anhidritler ile emprenye edilen ve ardından 2, 4 ve 8 saat boyunca $120^{\circ} \mathrm{C}$ 'de modifikasyona tabi tutulan sarıçam odunu örneklerinin su alma oranı, boyutsal kararlılık ve mantar çürüklüğüne karşı dayanımı belirlenmiştir. Modifiye edilen örneklerin kimyasal yapısı FT-IR spektroskopisi ile karakterize edilmiştir. Elde edilen bulgular 1 şı̆̆ında, propiyonik anhidrit modifikasyonunun, oduna daha iyi bir boyutsal kararlılık ve mantar çürüklüğüne karşı daha iyi bir dayanım özelliği kazandırdığı bulunmuştur. Fitalik anhidrit modifikasyonu ise, araştırılan parametreler bakımından en kötü sonucu veren anhidrit olmuştur. Reaksiyon süresinin odunun ağırlık artış, su alma ve boyutsal kararlılık değerlerine çok fazla etkisinin olmadığı ancak süre arttıkça $C$. puteana mantarının saldırısı nedeniyle oluşan ağırlık kaybının azaldığı bulunmuştur. FT-IR spektroskopisi odun bileşenlerinde değişimler ve kimyasal bağlanmalar olduğunu göstermiştir.

\section{KAYNAKLAR (REFERENCES)}

1. Homan, W.J. ve Jorissen, A.J.M., "Wood Modification Developments", Heron, Cilt 49, No 4, 361-386, 2004.

2. Rowell, R.M., Tillman, A.M. ve Simonson, R., "Dimensional Stability of Particleboard Made From Vapour Phase Acetylated Pine Wood Chips", Nordic Pulp and Paper, Cilt 1, No 2, 11 17, 1986.

3. Tarkow, H., Stamm, A.J. ve Erickson, E.C.O., "Acetylated Wood", USDA Forest Service Forest Products Lab., Report No 1593, 1950.

4. Rowell, R.M. ve Ellis, W.D., "Determination of Dimensional Stabilization of Wood Using The Water- Soak Method", Wood and Fiber Sci., Cilt 10, No 2, 104-111, 1978.

5. Militz, H., "Improvements of Stability and Durability of Beech-Wood (Fagus Sylvatica) by Means of Treatment with Acetic Anhydride", Proc. $22^{\text {nd }}$ Ann. meeting Int. Res. Group Wood Preservation, Kyoto, Japan, IRG-WP 3645, 1991.

6. Beckers, E.P.J. ve Militz, H., "Acetylation of Solid Wood Initial Trials on Lab and Semi Industrial Scale", Proc. $2^{\text {nd }}$ Pasific Rim BioBased Composites Symposium, Vancouver, Canada, 125-134, 1994.

7. Nilsson, T., Rowell, R.M., Simonson, R. ve Tillman, A.M., "Fungal Resistance of Pine Particle Boards Made from Various Types Acetylated Chips", Holzforschung, Cilt 42, No 2, 123-146, 1988.

8. Rowell, R.M., Esenther, G.R., Nicholas, D.D. ve Nilsson, T., "Biological Resistance of Southern Pine and Aspen Flakeboards Made From Acetylated Flakes", J. Wood Chemistry Tech., Cilt 7, No 3, 427-440, 1987.

9. Takahashi, M., Imamura,Y. ve Tanahashi, I., "Effect of Acetylation on Decay Resistance of Wood Against Brown Rot, White Rot and Soft Rot Fungi”, Proc. 20 ${ }^{\text {th }}$ Ann. Meeting Int. Res. Group Wood Preservation, Lappeenranta, Finland, IRG-WP 3540, 1989.

10. Larsson Brelid P., Simonson R. ve Bergman O., "Resistance of Acetylated Wood to Biological Degradation", Holz Als Roh und Werkstoff, Cilt 58, 331-337, 2000.

11. Hill, C.A.S., Wood Modification Chemical Thermal and Other Processes, John Wiley \& Sons, Germany, 2006.

12. Rowell, R.M., "Chemical Modification: A NonToxic Approach to Wood Preservation", Drewno, Cilt 48, No 173,111-117, 2005.

13. Hill, C.A.S. ve Jones, D., "Dimensional Changes in Corsican Pine Sapwood due to Chemical Modification with Linear Chain Anhydrides", Holzforschung, Cilt 53, 267-271, 1999. 
14. Li, L.Z., Furuno, T., Katoh, S. ve Uehara, T., "Chemical Modification of Wood by Anhydrides without Solvents or Catalysts", J. of Wood Sci., Cilt 46, No 3, 215-221, 2000.

15. Li, L.Z., Furuno, T. ve Katoh, S., "Preparation and Properties of Acetylated and Propionylated WoodSilicate Composite", Holzforschung, Cilt 55, 9396, 2001.

16. Li, L.Z., Furuno, T. ve Katoh, S., "Wood Propionylation in the Presence of Catalysts", Wood and Fiber Sci., Cilt 33, No 2, 255-263, 2001.

17. Chang, S.T. ve Chang, H.T., "Comparisons of the Photostability of Esterified Wood", Polymer Degradation and Stability, Cilt 71, No 2, 261266, 2001.

18. Chauhan, S.S., Aggarwal, P., Karmarkar, A. ve Pandey, K.K., "Moisture Adsorption Behaviour of Esterified Rubber Wood (Hevea brasiliensis)", Holz als Roh- und Werkstoff, Cilt 59, No 4, 250253, 2001.

19. Çetin, N. S. ve Özmen, N., "Dimensional Changes in Corsican Pine Sapwood due to Reaction with Crotonic Anhydride", Wood Sci. and Tech., Cilt 35, No 3, 257-267, 2001.

20. Papadopoulos A.N. ve Hill, C.A.S., "The Biological Effectiveness of Wood Modified With Linear Chain Carboxylic Acid Anhydrides Against Coniophora puteana", Holz als Roh- und Werkstoff, Cilt 60, 329-332, 2002.

21. Papadopoulos, A.N. ve Gkaraveli, A., "Dimensional Stabilisation and Strength of Particleboard by Chemical Modification with Propionic Anhydride", Holz als Roh-und Werkstoff, Cilt 61, No 2, 142-144, 2003.

22. Papadopoulos, A.N., "Moisture Adsorption Isotherms of Two Esterified Greek Hardwoods", Holz als Roh- und Werkstoff, Cilt 63, 123-128, 2005.

23. Dizman, E., Kimyasal Modifikasyonun Kızılağaç ve Ladin Yongalevhalarında Fiziksel, Mekanik ve Biyolojik Özelliklere Etkisi, Yüksek Lisans Tezi, KTÜ, FBE, 2005.

24. Serin, Z., Süksinik Anhidrit Modifikasyonunun Orta Yoğunluktaki Lif Levhanın (MDF) Özelliklerine Etkisi, Doktora Tezi, KTÜ, FBE, 2005.

25. Çetin, N.S. ve Ozmen, N., "Modification of Wood with Environmentally Friendly Chemicals to Improve Decay Resistance", J. of Environmental Biology, Cilt 26, No 4, 735-740, 2005.

26. Çetin, N.S., Gültekin, G., Özmen, N. ve Birinci, E., "Propionik Anhidrit Modifikasyonu ile Eucalyptus Grandis W. Hill Ex Maiden Diri Odununa Boyutsal Sabitlik Kazandırılması",
Bartın Orman Fakültesi Dergisi, Cilt 2, 647655,2009

27. Youngquist, J.A., Krzysik, A. ve Rowell, R.M., "Dimensional Stability of Acetylated Apsen Flakeboard", Wood and Fiber Sci., Cilt 18, No 1, 90-98, 1986.

28. EN 113, Determination of the Toxic Values Against Wood Destroying Basidiomycetes Cultured on Agar Medium, European Standard, 1994.

29. Sun, R. ve Sun, X.F., "Structural and Thermal Characterization of Acetylated Rice, Wheat, Rye, Barley Straws and Poplar Wood Fibre", Industrial Crops and Products, Cilt 16, No 3, 225-235, 2002.

30. Rowell, R.M., Simonsen, R. ve Tillman, A.M., "Acetyl Balance for The Acetylation of Wood Particles by A Simplified Procedure", Holzforschung, Cilt 44, 263-269, 1990.

31. Temiz, A., Dış Hava Koşullarının Emprenyeli Ağaç Malzemeye Etkileri, Doktora Tezi, KTÜ, FBE, 2005.

32. Tshabalala, M.A., Jakes, J., VanLandingham, M.R., Wang, S., Peltonen, J., "Surface Characterization", Handbook of Wood Chemistry and Wood Composites, Second ed., Editör: Rowell, R.M., CRC Books, 217-252, 2013.

33. Ximenes, F.A. ve Evans, P.D., "Protection of Wood Using Oxy-Aluminum Compounds", Forest Products Journal, Cilt 56, No 11-12, 116122, 2006.

34. Nadal, L.M.K., Cararo, D.C., Pinheiro, L.A. ve Prestes, R.A., "Optimization of Wood Flour Acetylation by Factorial Design and Partial Least Squares Regression", Quím. Nova, Cilt 35, No 9, 1763-1766, 2012.

35. Rowell, R.M., Youngquist, J.A. ve Montrey, H.M., "Chemical Modification Adding Value Through New FPL Composite Technology", Forest Products Journal, Cilt 38, 67-70, 1988.

36. Papadopoulos, A. ve Hill, C.A.S., "The Sorption of Water Vapour by Anhydride Modified Softwood", Wood Sci. and Tech., Cilt 37, 221231, 2003.

37. Kumar, S., "Chemical Modification of Wood", Wood and Fiber Sci., Cilt 26, No 2, 270-280, 1994.

38. Matsuda, H., "Preparation and Utilization of Esterified Wood Bearib Carboxyl Groups", Wood Science Techn., Cilt 21, 75-88, 1987.

39. Chen C.G., "Fungal Resistance of Loblolly Pine Reacted With Para-Toluene Sulfonyl Chloride or Isocyanate", Wood and Fiber Sci., Cilt 24, No 2,161-167, 1992. 